\title{
DISCURSO PROFERIDO POR OCASIÃO DA POSSE DOS PROFESSORES \\ TITULARES NOMEADOS NO ANO DE 2007
}

SPEECH DUE TO THE INVESTITURE AS FULL PROFESSORS NOMINATED IN THE YEAR 2007

Antonio Scarance Fernandes*

Excelentíssimo Senhor Diretor,

Excelentíssimo. Senhor Vice-Diretor,

Douta Congregação,

Excelentíssimo Professor Antonio Magalhães Gomes Filho que, em nome do Colégio de Professores, saudou os novos professores titulares,

Excelentíssimos Professores José Roberto dos Santos Bedaque, Ignácio Maria Poveda Velasco, José Rogério Cruz e Tucci e Paulo Borba Casella, que, comigo, dividem a alegria desse momento solene,

Demais professores presentes,

Dignas autoridades,

Meus senhores,

Minhas senhoras,

Estimados estudantes,

Mais uma vez abrem-se as portas do Salão Nobre de nossa querida Faculdade de Direito e reúne-se a egrégia Congregação para receber cinco novos Professores Titulares. Repete-se um antigo ritual. Para o saudoso professor Guido Fernando Silva Soares, cuja vaga é assumida pelo professor Paulo Borba Casella, um dos novos titulares, inspirado em cerimonial da Idade Média, esse rito significava, à semelhança da investidura de um cavaleiro, a passagem de um estamento social a outro, com atributos mais elevados que a sociedade outorgava a alguém. Para essa outorga, pressupunha-se um periodo de formação e treinamento, como forma de preparo do novo cavaleiro para as futuras lides e o atingimento de um grau elevado de aprimoramento que o habilitava para as suas novas responsabilidades". É uma feliz síntese do que esse momento representa. Um novo professor titular é alguém que, depois de seu aperfeiçoamento pelos longos anos de exercício da profissão, pelo estudo contínuo, pela pesquisa, pela elaboração de seus trabalhos, dissertações e teses é moldado para, quando alcançar o ápice de sua carreira, estar apto para as suas novas responsabilidades.

Hoje se repete esse ritual em uma ocasião muito especial para a nossa Faculdade. $\mathrm{O}$ fato de um de seus membros ascender ao último grau da carreira universitária já seria motivo de grande júbilo, pois é com a contínua sucessão de seus professores titulares que a nossa instituição secular se mantém viva, atuante e apta a enfrentar novos

* Professor Titular de Direito Processual Civil do Departamento de Direito Processual da Faculdade de Direito da Universidade de São Paulo. 
desafios. Preserva o que foi edificado e prossegue na sua eterna e interminável construção, agora com um professor longamente preparado para enfrentar as novas lutas e responder às modernas exigências. Que dizer então de um momento como esse em que são empossados cinco novos professores titulares?

Para mim, a ocasião é, ainda, mais significativa. Tive a imensa honra de, por ser o mais antigo, ser escolhido para falar em nome de todos os novos titulares.

Como dar conta, contudo, desse difícil encargo? Como expressar os sentimentos aninhados nos corações de todos nós? Sentimentos que se misturam e se entrelaçam num torvelinho de emoções: lembrança dos longos anos percorridos nesta escola; dos difíceis concursos a que nos submetemos, das palavras de amparo dos amigos nos momentos em que o ideal de ser professor titular devia ser adiado; satisfação pela concretização final de nosso objetivo; esperança pelo que poderemos fazer e dúvida sobre os caminhos a ainda serem trilhados.

Cada uma de nossas trajetórias é experiência única, pessoal, difícil de ser traduzida por outro, mas acredito ser, para todos nós, esse momento uma manifestação de fé, de esperança, de reflexão, de louvor e de agradecimento, aspectos essenciais de uma oração comum de posse.

Somos uma manifestação viva de fé, de crença em nossa Faculdade, na Universidade, no ensino público e diferenciado que ela proporciona. É porque acreditamos em nossa escola, em seu ideal de justiça, em sua luta pelo respeito aos direitos humanos fundamentais e pela preservação dos princípios democráticos, em seu proeminente papel na vida de nossa sociedade, que, nos momentos de desânimo, de aflição, de angústia, de incerteza, arrumávamos força para continuar na perseguição de nosso objetivo, enfrentando todos os obstáculos, removendo verdadeiras montanhas. Só essa fé explica a nossa conquista.

Mas esse é também um momento de esperança para todos nós, esperança de sermos capazes de dar continuidade ao trabalho dos que nos antecederam e, principalmente, dos que diretamente sucedemos e sermos ainda a alma nova necessária para que a faculdade esteja sempre renascendo, dando seqüência à sua pujante história, sendo sempre a Velha e Nova Academia. Esperamos ter força suficiente para as novas lides, coragem necessária para inovar, para criar, para arriscar, sem temer, cientes de que pelo erro muito se aprende.

Vem-me à mente o fato de a Faculdade estar se aproximando de seu bicentenário, tendo já superado cento e oitenta anos de vida. Por ela passaram professores que, desde o período imperial, souberam ajustá-la ao seu tempo. Também nós, novos titulares, esperamos poder alinhar a escola às imposições dos tempos atuais, apesar das dúvidas que nos cercam sobre o futuro do ensino em geral e especialmente do ensino 
jurídico. Como deverá ser ele em época de crescente informatização, de globalização, de rompimento de fronteiras, de inimagináveis avanços tecnológicos?

A maneira de ministrar conhecimento deve sofrer profundas modificações. Exposições longas como as memoráveis aulas de nossos professores catedráticos para uma enorme sala, repleta de alunos, cada vez mais ficam reservadas a aulas inaugurais e a conferências especiais. O professor titular de hoje deve trabalhar em grupo, afinado com outros professores de seu Departamento e, até mesmo, de outras faculdades, mediante a fixação de linhas determinadas de pesquisa. As suas aulas presenciais devem ser direcionadas para um número menor de alunos, a fim de que deles se aproxime e possa melhor cumprir a sua atual missão. Dele se espera que vá além da simples transmissão de conhecimento do direito positivo na forma exposta nos manuais, levando o seu aluno, do bacharelado e mais ainda dos cursos de pós-graduação, a teorizar, a refletir, a criticar, a discernir, de modo a compreender quando a norma posta é constitucional, é justa, é legítima.

Abro, aqui, um parêntese, para cumprimentar a Congregação e o nosso Diretor, professor João Grandino Rodas, pela divisão das classes em duas, anseio de todos nós. Será agora possível estreitar o contato com os nossos alunos, melhor conhecê-los e, com isso, melhor formá-los.

Hoje, é também momento de nós, novos professores titulares, refletirmos sobre as nossas trajetórias e de louvarmos os professores cujos cargos passamos a ocupar.

Aqui comecei em 1966, tendo freqüentado os bancos acadêmicos em momentos muito difíceis da História brasileira, em que foram suprimidos importantes direitos do cidadão, mas jamais a nossa escola se calou. Logo após estar formado, em 1970, iniciei a minha carreira no Ministério Público, onde permaneci por vinte e três anos, mas sempre acalentei o sonho de ser professor dessa Casa. Isso ocorreu pelas mãos de Cândido Rangel Dinamarco, meu orientador no Mestrado e no Doutorado. Sob sua orientação produzi os meus primeiros trabalhos sobre a questão prejudicial e depois sobre o incidente processual, ambos com enfoque direcionado à teoria geral do processo. Passei a auxiliá-lo nos seminários do Curso de Pós-Graduação. Depois, por seu intermédio, vim a trabalhar com Ada Pellegrini Grinover, colaborando nas aulas de processo penal. Com ela e o professor Antonio Magalhães Gomes Filho, a quem cumprimento pela saudação a nós, novos professores titulares, pude realizar intenso trabalho, no Curso de Pós-Graduação e na confecção de diversas obras jurídicas. Como ascendi ao cargo de titular há três anos, já iniciei a minha proposta de intensificar a linha de pesquisa sobre a eficiência e o garantismo no processo penal, dando seqüência a trabalhos anteriormente feitos, especialmente o Processo Penal Constitucional, e contando, agora, com a colaboração eficiente dos professores José Raul Gavião de Almeida e Maurício Zanóide de Moraes. 
O professor José Roberto dos Santos Bedaque se diplomou em Taubaté. Também começou nessa Faculdade auxiliando o professor Cândido Dinamarco, seu orientador, persistindo nessa tarefa por longos anos, principalmente pela coordenação dos seminários do Curso de Pós-Graduação. Com suas aulas, com sua dedicação ao magistério, com sua cultura, com seu profundo conhecimento de processo civil, com sua visão moderna no sentido da instrumentalização e da flexibilização do processo, expostas em suas teses, conquistou a nossa Casa e os nossos alunos, como prova a sua escolha para paraninfo de várias turmas de formandos. A sua produção é voltada a temas atuais do direito processual, como seus estudos a respeito da tutela antecipada e a tutela cautelar, da influência do direito material sobre o processo, da efetividade do processo e técnica processual. Alcançou os mais elevados graus em todas as instituições de que participou: procurador de Justiça no Ministério Público, desembargador na Magistratura e Professor Titular nessa Faculdade.

O professor José Rogério Cruz e Tucci, aqui se formou em 1978, e desde logo mostrou vocação para a pesquisa e para o ensino. Exerceu já durante o curso atividade de monitoria, e quatro anos depois de formado completava na Faculdade de Direito de Roma o seu doutoramento, revalidado em 1986 por nossa escola, onde fez ainda o mestrado e a livre-docência. Recordo-me quando, depois de ter completado seus estudos na Europa, iniciou o seu mister de professor em nosso Departamento, dedicando-se, particularmente, ao ensino da História do Processo Civil no Curso de Pós Graduação, desde 1989, em perfeita sintonia com o professor Luiz Carlos de Azevedo. Além de suas atividades de magistério, prestou importantes serviços à nossa Instituição, nas variadas comissões de que participou e na direção por vários anos da Comissão de Pós Graduação. É bem expressiva a sua produção científica, com obras sobre os mais diversos temas do processo civil motivação da sentença, monitória, objeto litigioso, coisa julgada. Advogado renomado foi presidente da Associação dos Advogados de São Paulo.

Difícil, neste curto espaço de tempo, louvar aos professores que, no Departamento de Direito Processual, sucedemos: Ada Pellegrini Grinover, Antonio Carlos de Araújo Cintra e José Ignácio Botelho de Mesquita.

A professora Ada Pellegrini Grinover, com suas valiosas obras, com seus escritos, com seus ensinamentos, foi responsável pelo aprofundamento dos estudos do processo penal à luz dos princípios e regras constitucionais, incutindo nas mentes dos doutrinadores, dos operadores do Direito, dos estudantes a necessidade de, conforme ela própria disse, "verificar a adequação das leis à letra e ao espírito da Constituição" A professora Ada levou ao Exterior o seu profundo conhecimento e domínio do processo penal. Teve e tem destacado papel no Instituto Ibero-Americano de Direito Processual e é a mola propulsora do Instituto Brasileiro de Direito Processual. Com tudo isso, exerceu forte influência no pensamento que norteia o processo penal entre nós, na América Latina 
e na Europa. Para mim, sempre foi um privilégio trabalhar com a professora Ada e, agora, uma elevada honra sucedê-la, seguindo na cátedra de renomados mestres do Processo Penal brasileiro.

O professor Antonio Carlos de Araújo Cintra enriqueceu o nosso Departamento com o seu ensino na Graduação e na Pós-Graduação e engrandeceu o Processo Civil nacional com suas obras, como o volume IV, sobre prova, audiência, sentença e coisa julgada, dos Comentários ao Código de Processo Civil da Forense que compõe importantíssima coleção de Direito Processual Civil do País; o trabalho sobre motivo e motivação do ato administrativo; os livros derivados de suas teses sobre os limites objetivos da apelação civil, sobre o chamamento à autoria, sobre o litisconsórcio unitário. Além de conceituado professor e jurista, foi brilhante advogado, vindo a integrar, pelo quinto constitucional, dois Tribunais de Alçada, e, por fim, o Tribunal de Justiça. O seu desempenho no Poder Judiciário, bem como o dos professores Luiz Carlos de Azevedo e José Roberto dos Santos Bedaque, oriundos da Advocacia e do Ministério Público, mostra a importância da manutenção do quinto constitucional, objeto de injustificável contestação por algumas entidades de classe.

O professor José Ignacio Botelho de Mesquita esteve em nosso Departamento por longos anos, ali prestando inestimáveis serviços. Sempre interessado na vida da Faculdade, teve intensa participação em seus organismos internos e exerceu forte influência nas decisões de nossos órgãos colegiados. Escreveu e continua escrevendo livros de relevante significado para o Processo Civil brasileiro, como o seu memorável trabalho sobre a ação civil, o seu precioso livro sobre a coisa julgada. Foi dedicado professor, é renomado advogado, culto consultor e parecerista, tendo, para nossa felicidade, reunido o farto material produzido nessas atividades em três volumes intitulados Teses, Estudos e Pareceres. Bem evidencia o seu valor como professor, como jurista, como homem preocupado com os problemas da vida social e política do País, o fato de, após a sua aposentadoria, serem tantas as homenagens que lhe foram prestadas.

Além de nós, professores do Departamento de Processo, assumem a titularidade nessa noite outros dois professores.

O professor Ignacio Maria Poveda Velasco bacharelou-se em 1982, foi orientado pelo Professor Alexandre Augusto de Castro Corrêa, no Mestrado e no Doutorado, obtendo o título de livre-docente em História do Direito, em 2000. Sempre se dedicou a estudar a História do Direito, escrevendo importantes obras a respeito, como a Proteção do Comprador no Direito Romano, A execução do devedor no Direito Romano e também no Direito intermédio e, mais recentemente, os esponsais no Direito luso-brasileiro. Soube tornar o seu trabalho nessa escola um verdadeiro sacerdócio, dedicando-se de corpo e alma às suas incumbências de professor e às suas outras atividades. Presidiu diversas comissões: a de informática, a que organizou a semana de recepção dos calouros, a do museu. Desde 
2004, dirigia o Departamento de Pós Graduação, ao qual deu decisivo impulso, deixando-o recentemente porque, em virtude de seus reconhecidos méritos, foi chamado para exercer a difícil atividade de vice-diretor da Faculdade de Direito de Ribeirão Preto.

Ocupa a vaga do professor Luiz Carlos de Azevedo, o qual, por bastante tempo, foi professor do Departamento de Direito Processual, de onde saiu para ser o primeiro titular da disciplina História do Direito, quando ela voltou a integrar o currículo da Faculdade. Essa cadeira fizera parte do Curso de Direito no século XIX, mas fora suprimida em 1901. Professor Azevedo sempre mostrou inclinação aos estudos de História do Direito, herdada talvez dos tempos em que foi orientado pelo professor Moacyr Lobo da Costa, também dedicado ao estudo histórico do Direito Processual. Divide, desde 1989, com o professor José Rogério Cruz e Tucci a regência das aulas de História do Processo Civil Romano, Canônico e Lusitano. Também advogado, integrou o Poder Judiciário, como juiz do Primeiro Tribunal de Alçada Civil de São Paulo e depois desembargador. Dirige importante centro universitário, em Osasco, a UNIFIEO.

Paulo Borba Casella aqui se formou em 1982, e quatro anos depois conquistava o título de doutor nessa Escola, vindo a ser livre-docente em 1992, e, finalmente, atingiu o grau de titular de Direito Internacional Público em 2007. Produziu valioso conjunto de obras jurídicas, editadas no Brasil e no Exterior. Além de coordenar cursos de pósgraduação nesta Faculdade, também o faz na Universidade de Estrasburgo. É professor visitante de universidades em Paris, Estrasburgo e Macau. Assim como o professor Guido Fernando Silva Soares, a quem sucede, foi orientado pelo professor Vicente Marotta Rangel. Deve-se a esse professor a continuidade do ensino de Direito Internacional Público nessa Escola, iniciado desde a sua criação. Foi a decisiva participação do professor Vicente Marotta Rangel que a manteve no currículo quando, em virtude de reforma do ensino, foi considerada opcional, deixando de ser lecionada em várias faculdades de Direito do País.

O professor Paulo Borba Casella toma assento no cargo deixado pelo saudoso professor Guido Soares, que dignificou a nossa Escola, como professor, como vice-diretor. Difundiu, como jurista, o seu conhecimento pelas obras que produziu, como o Curso de Direito Internacional Público, e, especialmente, as fundadas em profundos estudos sobre direito internacional e o meio ambiente. Expandiu o direito internacional. Formou mestres e doutores. Ministrou aulas com sabedoria e dedicação. Cumpriu assim, e muito bem, o seu compromisso, reafirmado por ocasião de sua posse "de servir aos interesses do Brasil, de profligar pelo desenvolvimento do Direito Internacional, em harmonia com os interesses da humanidade, e, em particular, de auxiliar com todas as suas forças e seu entusiasmo, na formação humanística, científica e profissional da juventude de nosso País". Por tudo isso, merece realce a justa homenagem a ele prestada por professores do Departamento e, entre eles, o professor Paulo Borba Casella, com a publicação de obra coletiva, intitulada Direito Internacional, Humanismo e Globalidade. 
Mas, como disse, esse momento é ainda de agradecimento.

O primeiro agradecimento deve ser dirigido a Deus, fonte de nossa energia e de nossa força. Merecem agradecimentos especiais as nossas famílias, razões principais de nossas existências. Peço, aqui, permissão aos outros professores, para cumprimentar suas famílias, pela minha, agradecendo às nossas esposas por Sueli, minha companheira de mais de quarenta anos, aos nossos filhos, genros e noras pelos meus - a Valéria e o Fábio, o Guilherme e a Vicki, a Fabiana e o Murilo, Janaína e Juliana, pela compreensão com as necessidades de estudo e pelos momentos furtados à nossa convivência. Dirijo-me ainda especialmente aos que, como eu, são avós, aos nossos netos pelos meus queridos, Fabinho, Valentina e Júlia ou Tomás. Peço, ainda, permissão aos demais professores para agradecer aos nossos pais pelo professor José Rogério Cruz e Tucci, que assume a titularidade no mesmo Departamento, onde, durante longo período, também foi titular o seu talentoso pai e dileto amigo, o professor Rogério Lauria Tucci. Agradecemos, ainda, a todos os nossos parentes, amigos, sempre presentes. Agradecemos a todos os funcionários dessa Casa, dos nossos Departamentos, da Biblioteca, do Setor de Pessoal, da Diretoria, sempre prestativos e prontos a colaborar. Agradecemos às instituições profissionais em que atuamos ou ainda continuamos a atuar, Ministério Público, Magistratura, Ordem dos Advogados, Associação dos Advogados de São Paulo, e, eu especialmente, a todos do ASF Cursos e Eventos.

É hora de encerrar.

Gostaria, então, de, em poucas palavras, dizer qual é no meu sentir e creio no dos demais quatro professores as nossas principais e comuns missões: a de manter vivos os ideais de justiça, de equilíbrio na aplicação do Direito, que sempre nortearam os caminhos de nossa Faculdade; a de preservar o elevado grau de ensino de nossa Escola e de continuar e incrementar as atividades de pesquisa, de extensão, de especialização; a de expandir ainda mais o seu raio de atuação pela maior aproximação com outras universidades nacionais e estrangeiras, e, principalmente, a de mostrar aos estudantes a necessidade de uma intransigente oposição aos que querem abalar o núcleo duro dos direitos fundamentais do indivíduo, com o risco de uma gradativa eliminação das nossas liberdades e, em virtude do desenvolvimento tecnológico, de uma perigosa permissividade na violação de nossa vida privada.

Muito obrigado.

São Paulo, Arcadas, em 28 de fevereiro de 2008. 


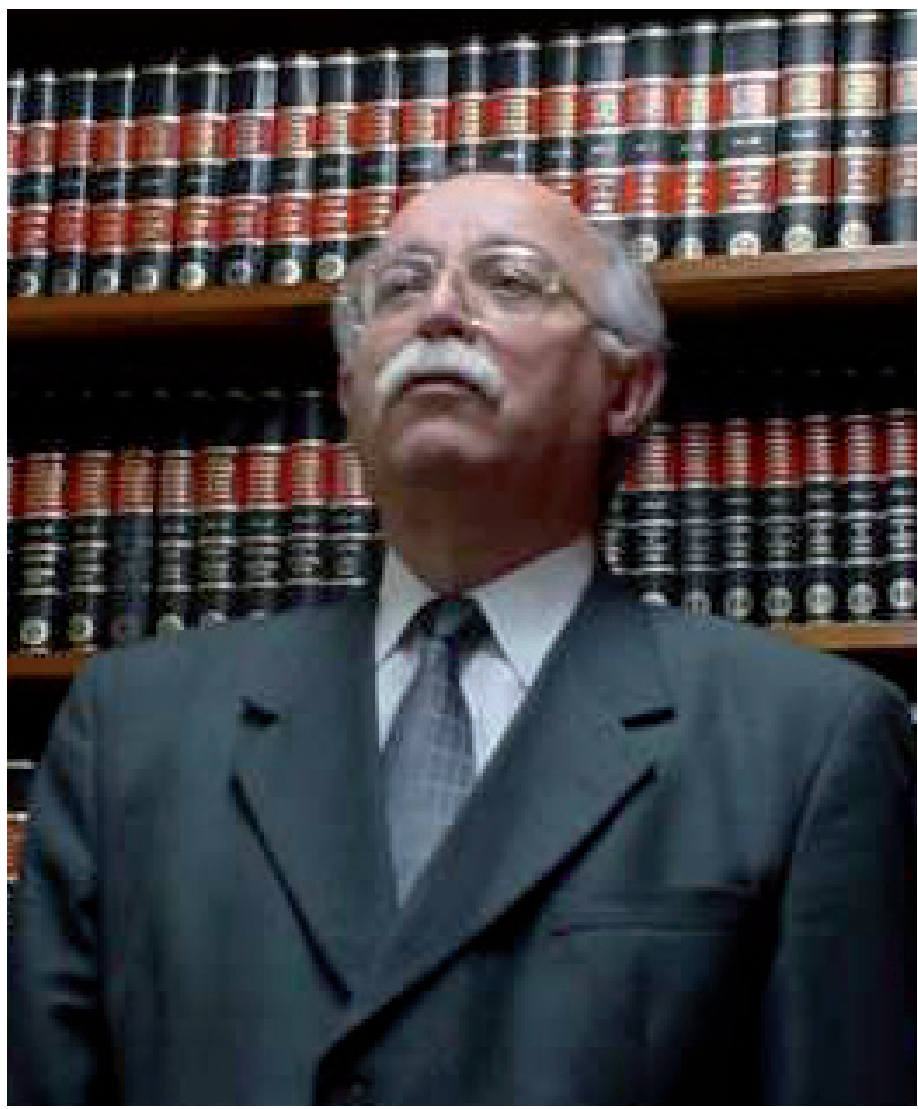

Professor Titular Antonio Scarance Fernandes 


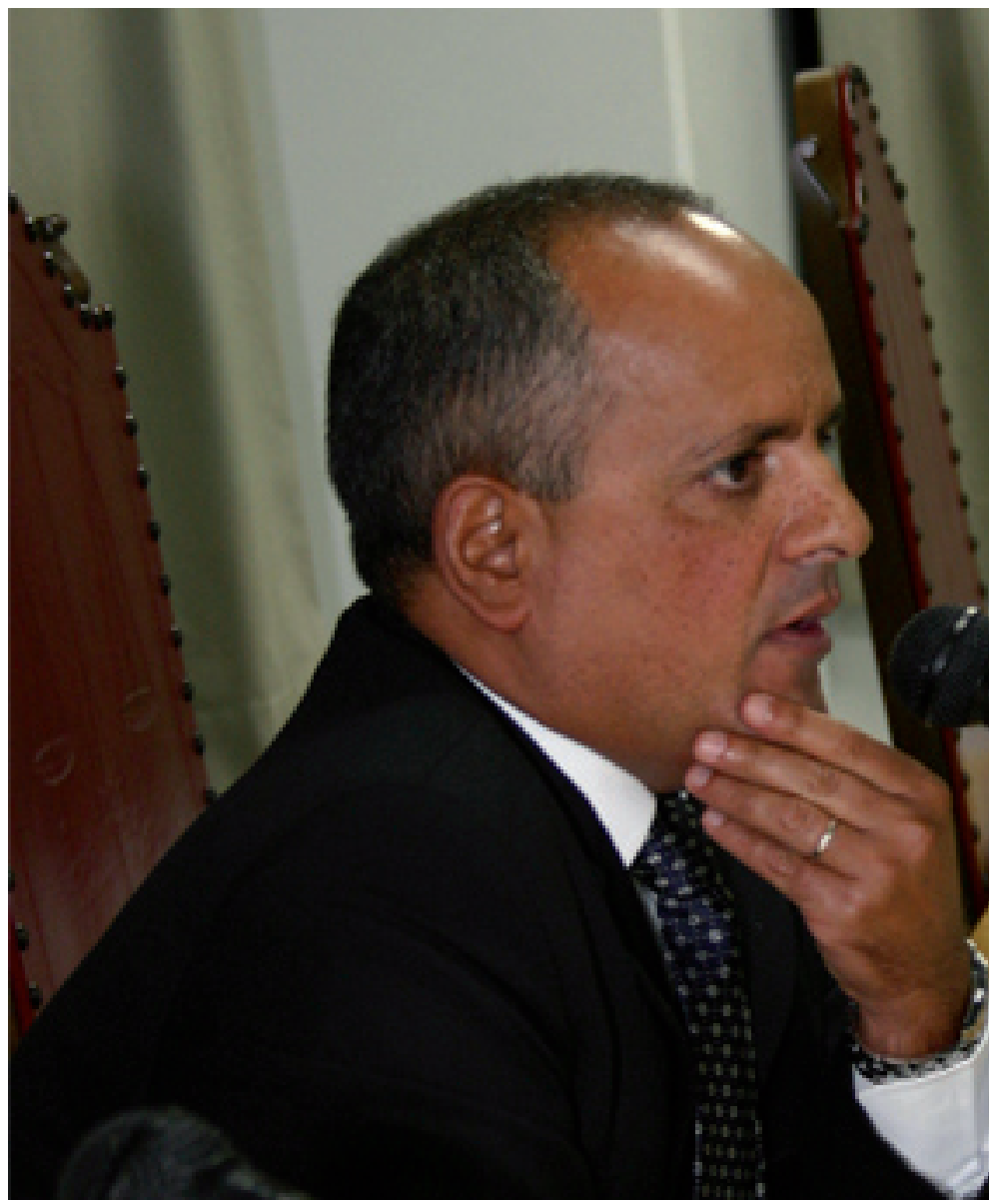

Professor Titular José Roberto dos Santos Bedaque 


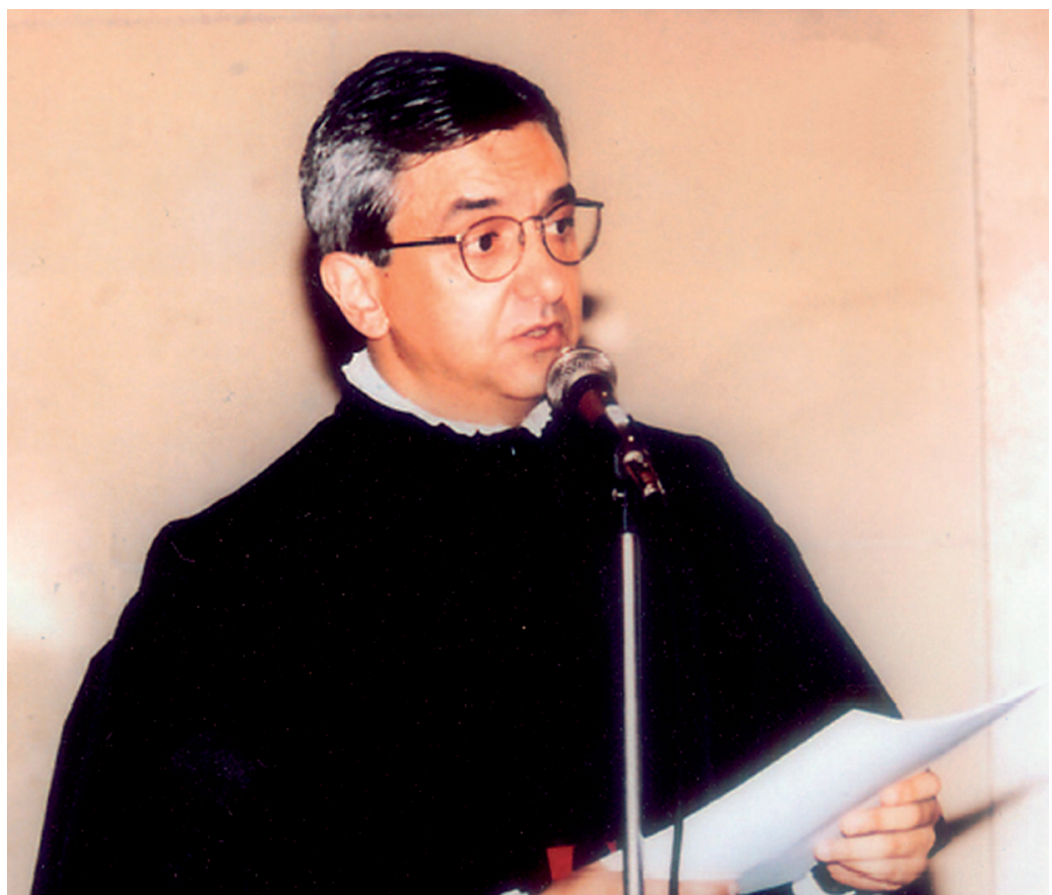

Professor Titular Ignacio Maria Poveda Velasco 


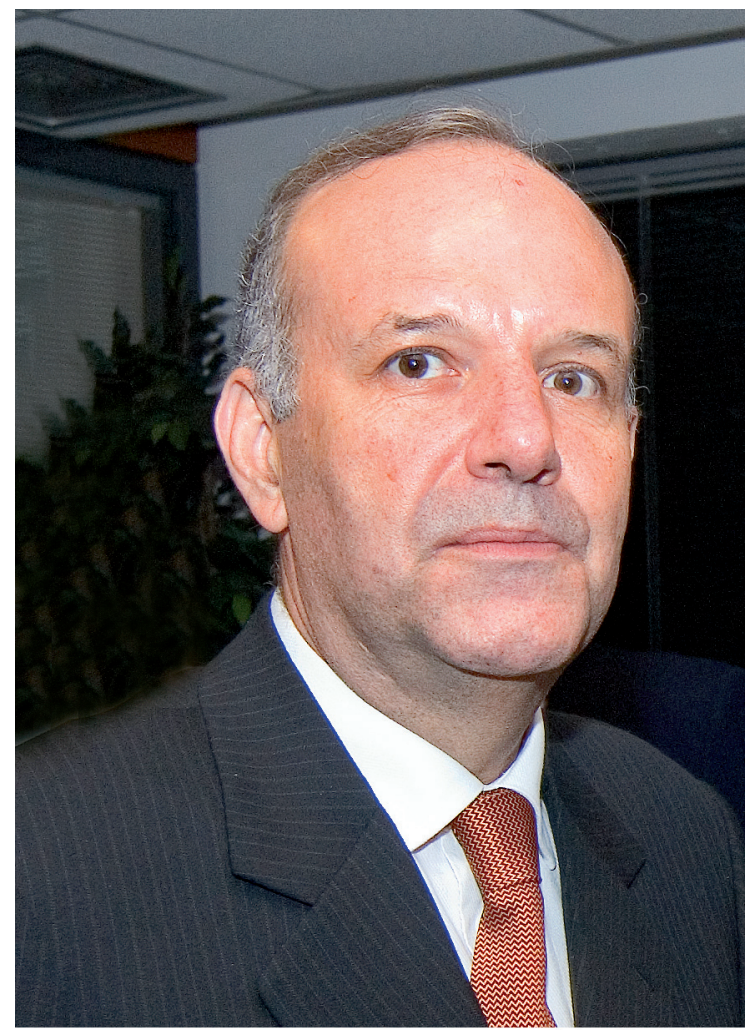

Professor Titular José Rogério Cruz e Tucci ${ }^{1}$

\footnotetext{
1 Foto: Aline Bassi.
} 


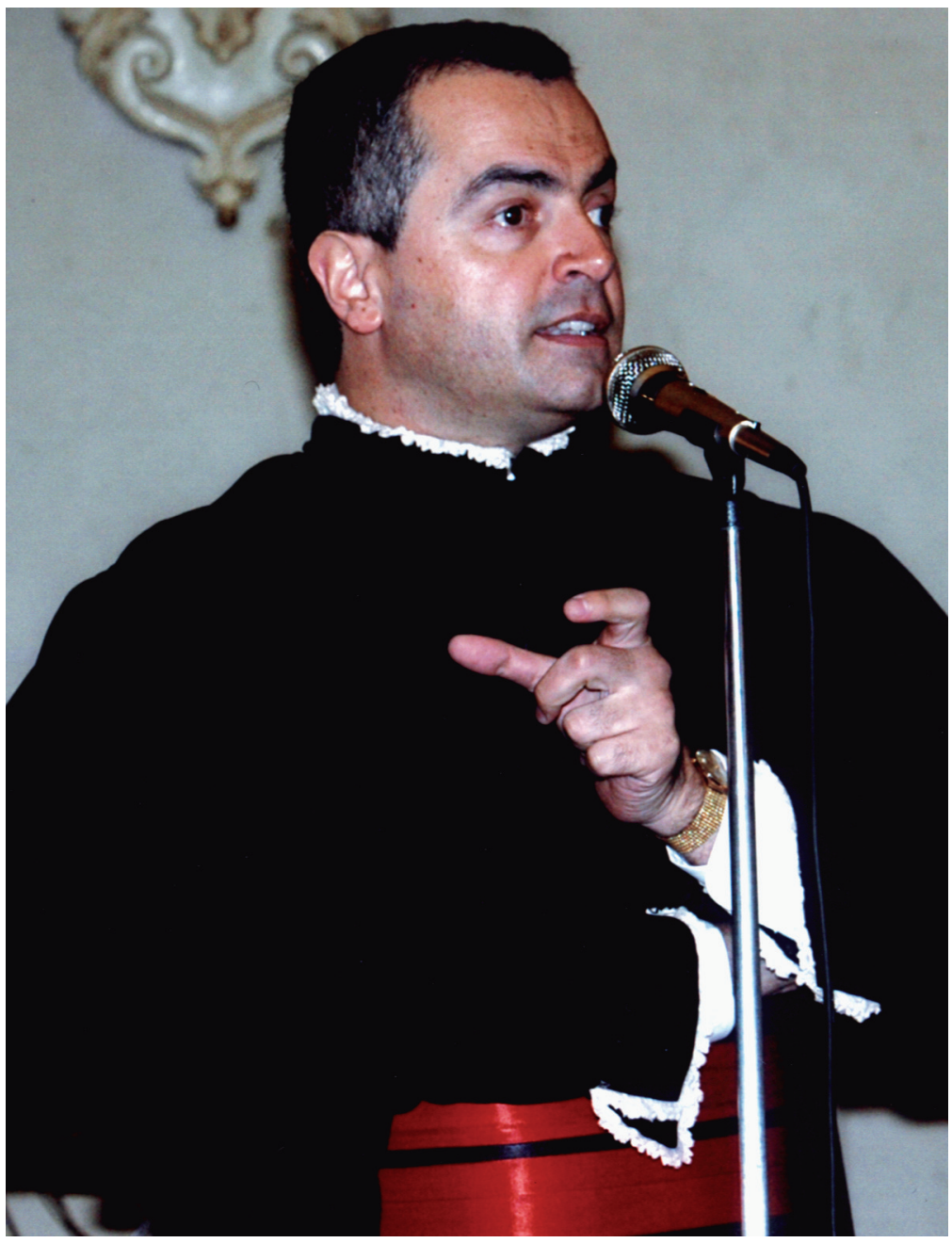

Professor Titular Paulo Borba Casella ${ }^{2}$

\footnotetext{
2 Foto: José da Silva Xavier.
} 